\title{
Analysis of the Phase Current Measurement Boundary of Three Shunt Sensing PWM Inverters and an Expansion Method
}

\author{
Byung-Geuk Cho*, Jung-Ik $\mathrm{Ha}^{\dagger}$, and Seung-Ki Sul ${ }^{*}$ \\ ${ }^{* \dagger}$ School of Electrical Engineering and Computer Science, Seoul National University, Seoul, Korea
}

\begin{abstract}
To obtain phase currents information in AC drives, shunt sensing technology is known to show great performance in cost-effectiveness and therefore it is widely used in low cost applications. However, shunt sensing methods are unable to acquire phase currents in certain operation conditions. This paper deals with the derivation of the boundary conditions for phase current reconstruction in three-shunt sensing inverters and proposes a voltage injection method to expand the measurable areas. As the boundary conditions are deeply dependent on the switching patterns, they are typically analyzed on the voltage vector plane for space vector pulse width modulation (SVPWM) and discontinuous pulse width modulation (DPWM). In the proposed method, the voltage injection and its compensation are conducted within one sampling period. This guarantees fast current reconstruction and the injected voltage is decided so as to minimize the current ripple. In addition to the voltage injection method, a sampling point shifting method is also introduced to improve the boundary conditions. Simulation and experimental results are presented to verify the boundary condition derivation and the effectiveness of the proposed voltage injection method.
\end{abstract}

Key words: Current reconstruction, PWM inverters, Shunt resistors, Three-shunt sensing

\section{INTRODUCTION}

Three-phase PWM inverters are widely used in industrial applications, especially in AC motor drive systems. In motor drives where instantaneous torque control is required, the phase currents flowing into the motor should be sensed. Thus far, a great deal of research on current sensing technologies such as shunts, current transformers, Rogowski coils, Hall effect sensors, Magneto Impedance sensors (MI), Giant Magneto Resistive (GMR) sensors, pilot devices in power semiconductors and optical current sensors has been conducted [1]-[25]. Each sensing method has its own strengths over other methods and is adopted into specific systems. In particular, shunt measurements detect shoot-through or short circuit faults, and show excellent integration in systems. These are also known to be the most cost-effective measurement types. Accordingly, they are broadly used for home appliances

Manuscript received Jun. 14, 2012; revised Jan. 22, 2012

Recommended for publication by Associate Editor Sanjeet K. Dwivedi.

${ }^{\dagger}$ Corresponding Author: jungikha@snu.ac.kr

Tel: +82-2-880-1760, Fax: +82-2-878-1452, Seoul National University

${ }^{*}$ School of Electrical Engineering and Computer Science, Seoul National University, Korea and in general-purpose motor control systems despite the losses that arise from the shunt resistors and the fact that the measurable phase currents are limited under certain conditions.

Figs. 1(a) and (b) show the typical configurations of shunt output phase current sensing inverters. These two circuits are referred to as a three-shunt sensing inverter (TSSI) and a single-shunt sensing inverter (SSSI), respectively. In the SSSI, the output phase currents are reconstructed with the DC link current. The relationship between the DC link current and the phase current was initially derived in [5]. Since then, numerous methods for phase current reconstruction based on an adjustment of the switching pattern or on estimators have been reported [5]-[21]. However, the SSSI has an inherent disadvantage in that simultaneous current sampling for two phases is impossible, resulting in errors in the instantaneous three-phase current information. In addition, because the DC shunt current can only be measured when an effective vector is applied, the average current during a switching period cannot be sampled. On the other hand, the TSSI allows for an independent and simultaneous measurement of each phase current. However, this method is associated with the losses of three-shunt resistors. Moreover, the efficiency is questionable 


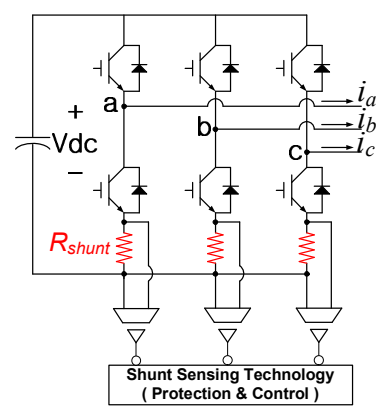

(a)

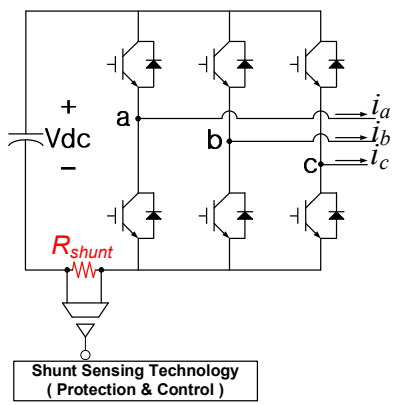

(b)
Fig. 1. Typical configurations of shunt output-phase current sensing inverters. : (a) Three-shunt sensing inverter(TSSI) and (b) single-shunt sensing inverter(SSSI).

in high-current applications. Nevertheless, the TSSI is an attractive and broadly applicable inverter configuration due to its simple reconstruction process and its potential for integration of the sensor in the power semiconductor switch itself.

Essentially, shunt sensing inverters show limited levels of performance owing to their inherently defective phase current reconstruction capability depending on the operating conditions. Various papers have attempted to identify and enhance the boundaries of the feasible phase current measurement range. However, most papers on the topic of shunt sensing inverters were unfortunately inclined towards the SSSI [5]-[21], while only a few works have examined the TSSI [22]-[25].

This paper deals with the TSSI and discusses its phase current measurement boundary. Previously, [22] analyzed and demonstrated its boundary on the voltage vector plane. It assumed that a zero vector would be long enough to guarantee the proper sampling of each current. However, this claim appears to be inaccurate, for reasons that are discussed later in this paper. References [23] and [24] also referred to the boundary, but analytical and descriptive expressions were not presented. References [21] and [25] depicted the precise boundary condition for both the TSSI and the SSSI. In this paper, on the other hand, the boundary is obtained more specifically with numerical formulas according to PWM schemes or shunt sensing strategies.

Based on the derivation, the phase current measurement range can be expanded. An estimator was applied in [24] when two or three phase currents were not simultaneously measurable. However, the system parameters and operating conditions have significant effects when using this method. As a result, the reliability of the reconstructed current is inconsistent. This paper proposes a voltage injection method based on that in [21] for the SSSI. Although current ripples are generated due to the injected voltage, they can be minimized with minimum magnitude voltage injection. In addition to the voltage injection method, a sampling point shifting method is also introduced to improve the boundary conditions.

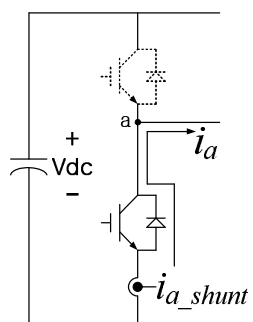

(a)

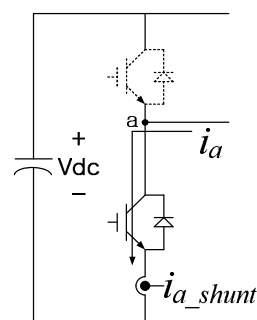

(b)
Fig. 2. Circuit state when the lower switch is on, (a) when positive current flows, and (b) when negative current flows.

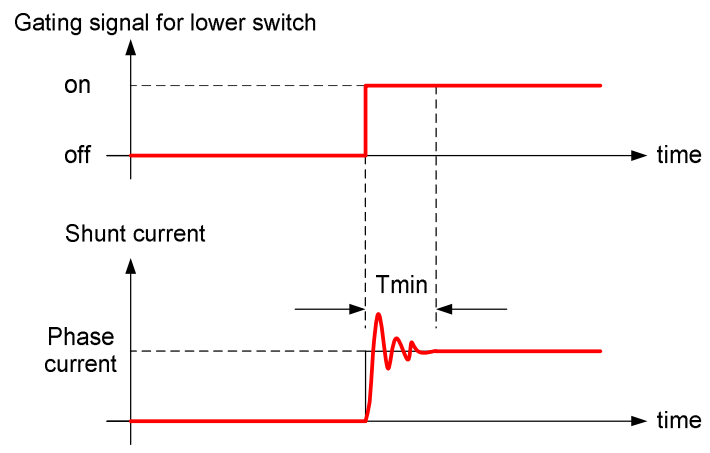

Fig. 3. Shunt current waveform.

TABLE I

Measurable Phase Currents Depending on the Switching STATE

\begin{tabular}{|c|c|}
\hline $\begin{array}{c}\text { Switching state } \\
(\mathrm{Sa}, \mathrm{Sb}, \mathrm{Sc})\end{array}$ & $\left.\begin{array}{c}\text { Shunt currents } \\
\left(i_{a} \text { shunt }\right. \\
i_{b} \text { shunt }\end{array} i_{c_{\_} \text {shunt }}\right)$ \\
\hline$(1,0,0)$ & $\left(0, i_{b}, i_{c}\right)$ \\
\hline$(1,1,0)$ & $\left(0,0, i_{c}\right)$ \\
\hline$(0,1,0)$ & $\left(i_{a}, 0, i_{c}\right)$ \\
\hline$(0,1,1)$ & $\left(i_{a}, 0,0\right)$ \\
\hline$(0,0,1)$ & $\left(i_{a}, i_{b}, 0\right)$ \\
\hline$(1,0,1)$ & $\left(0, i_{b}, 0\right)$ \\
\hline$(0,0,0)$ & $\left(i_{a}, i_{b}, i_{c}\right)$ \\
\hline$(1,1,1)$ & $(0,0,0)$ \\
\hline
\end{tabular}

Simulation and experimental results have been provided to demonstrate the effectiveness of this work.

\section{OPERATION BOUNDARY OF THE TSSI FOR PHASE CURRENT RECONSTRUCTION}

\section{A. Derivation of the Boundary Conditions}

To reconstruct phase currents, the shunt currents need to be investigated. Fig. 2 depicts the circuit state of phase 'a' when the lower switch is on. As shown in the figure, the shunt current corresponds to the phase current regardless of the current's direction/polarity. In short, the acquisition of the phase current information depends on the state of the lower switch. The measurable phase currents according to the switching states can be tabulated, as shown in Table I, for a 


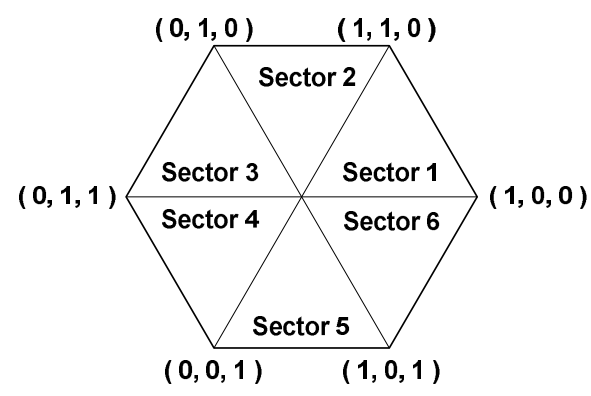

(a)

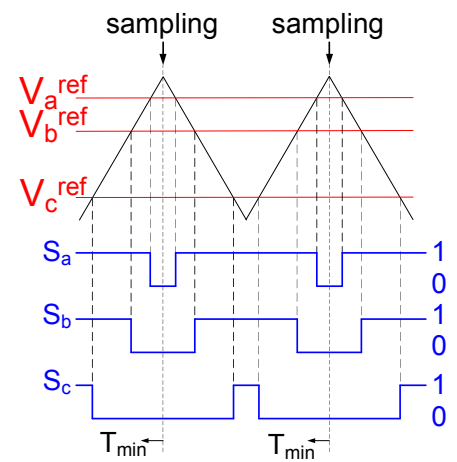

(b)

Fig. 4. Voltage vectors and corresponding switching patterns for SVPWM. : (a) Sector division of voltage plane and (b) switching patterns for sector 1

three-phase Voltage Source Inverter (VSI).

Switching state ' 1 ' indicates that the upper switch and the lower switch of the corresponding phase are on and off, respectively. State ' 0 ' indicates the reverse case. Therefore, when the switching state is $(1,0,0)$, the currents of phases ' $b$ ' and ' $c$ ' are measurable because the lower switches are on and no current flows through the shunt current of phase ' $a$ '.

In practice, when shunt currents are measured to reconstruct phase currents, the settling time of the shunt current must be considered. Due to the resonant effects caused by stray capacitances on the circuit and/or the reverse recovery of the diodes, the shunt current is not identical to the phase current during ' $T_{\text {min }}$ ', as shown in Fig. 3. Consequently, the shunt current must be measured at least ' $\mathrm{T}_{\text {min' }}$ ' after the lower switch is turned on for accurate phase current reconstruction. This defines the boundary condition for the TSSI.

Therefore, to reconstruct the phase current from a shunt current measurement after considering the given conditions, the switching patterns of an inverter should be identified. When SVPWM is applied for the PWM of a three-phase VSI, the switching patterns are determined according to the location of the voltage reference on the voltage plane, as defined in Fig. 4(a). Specifically, if the voltage vector is located in sector 1 , the switching patterns of the three phases are determined, as shown in Fig. 4(b). It can be deduced that current sampling is possible at the peaks of the carrier because the lower switches must be on. In addition, the minimum duration ' $\mathrm{T}_{\text {min }}$ ' of the lower switches must be assured and the current information of

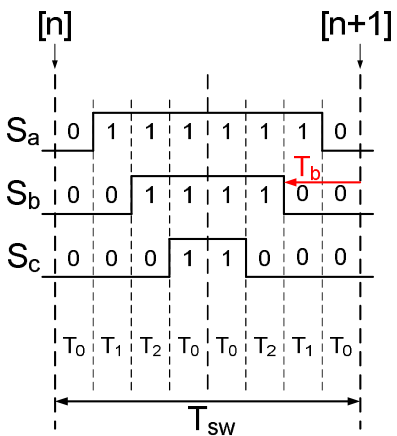

Fig. 5. Switching patterns in sector 1 for SVPWM.

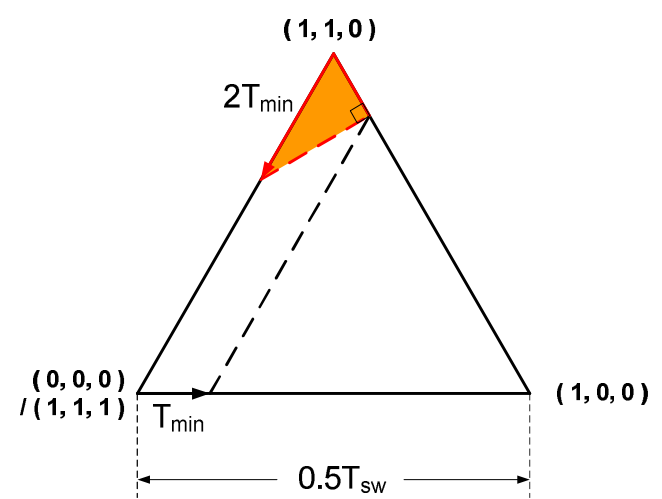

(a)

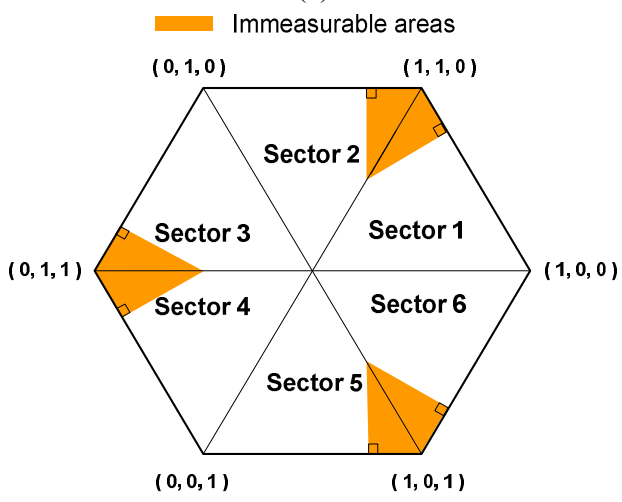

(b)

Fig. 6. Derivation of the immeasurable areas for SVPWM. : (a) Immeasurable area in sector 1, and (b) all immeasurable areas.

at least two phases is required for instantaneous control of the currents in $\mathrm{AC}$ drives.

To derive the boundary conditions in sector 1 for the TSSI while considering the above restraint, the switching states are re-depicted in Fig. 5. Here, $\mathrm{T}_{0}$ and $\mathrm{T}_{1} / \mathrm{T}_{2}$ denote the durations of the zero and effective vectors, respectively. In sector 1 , it is not necessary to measure the shunt current of phase ' $a$ ', which has the shortest duration, because the currents of the two phases are enough to identify the currents of all three phases in the $Y$ connection. Thus, $T_{b}$ needs to be longer than ' $T_{\min }$ ' for the measurement of the shunt currents in phases ' $b$ ' and ' $c$ '. In other words, if $T_{b}$ is less than ' $T_{\text {min }}$ ', three-phase current reconstruction is impossible, since the current of phase ' $c$ ' can only be reconstructed at most, and because this operating state 


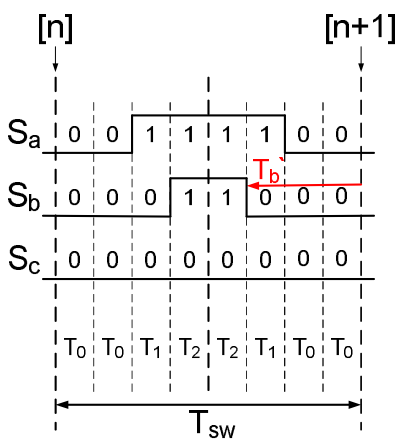

Fig. 7. Switching patterns in sector 1 for DPWM.

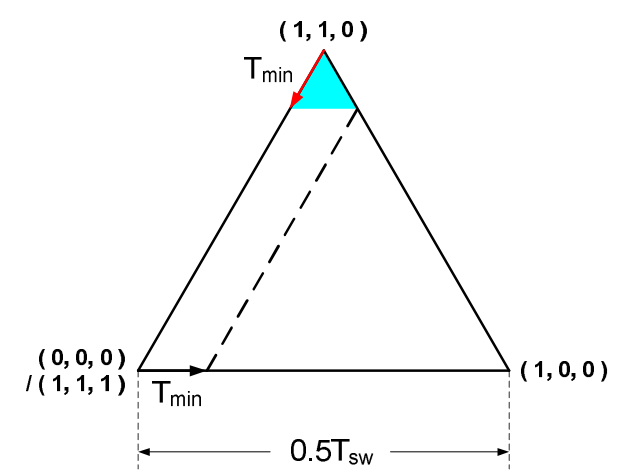

(a)

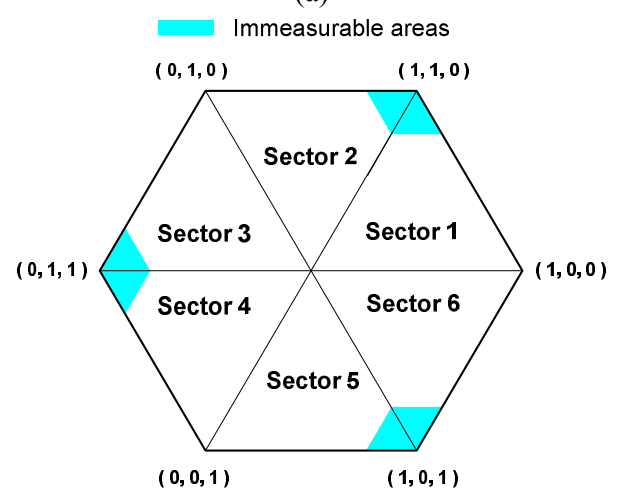

(b)

Fig. 8. Derivation of the immeasurable areas for DPWM. : (a) Immeasurable area in sector 1, and (b) all immeasurable areas.

is beyond the boundary conditions. Equations (1) thorough (3) show the mathematical expressions of the boundary conditions in sector 1 . The immeasurable areas are presented in yellow in Fig. 6.

$$
\begin{gathered}
T_{b}=T_{0}+T_{1}<T_{\min } \\
2 T_{0}+T_{1}+T_{2}=\frac{T_{s w}}{2}
\end{gathered}
$$

The result of equating (1) and (2), is as follows. :

$$
T_{2}>T_{1}+\frac{T_{s w}}{2}-2 T_{\min }
$$

By applying DPWM, the zero vector $(0,0,0)$ can be inserted instead of another zero vector $(1,1,1)$, as shown in Fig. 7 , and the

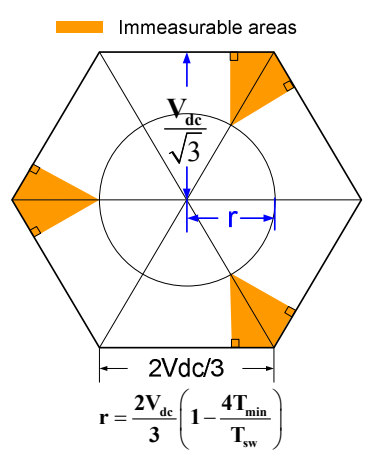

(a)

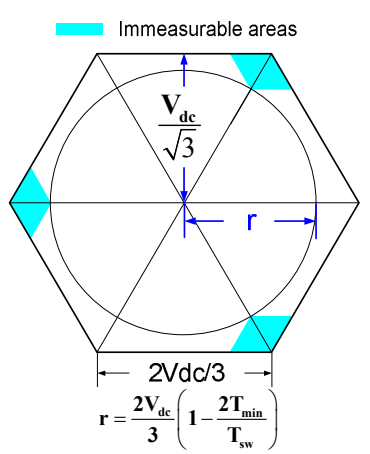

(b)
Fig. 9. Boundary magnitudes in the case of (a) SVPWM and (b) DPWM.

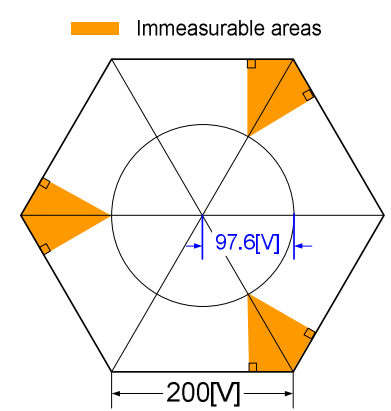

(a)

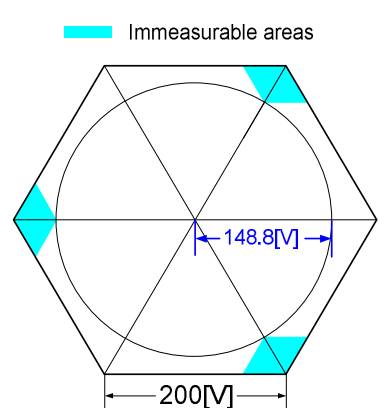

(b)
Fig. 10. Immeasurable areas for given system in the case of (a) SVPWM and (b) DPWM.

TABLE II

SySTEM SPECIFICATION

\begin{tabular}{|c|c|}
\hline DC link $\left(\mathrm{V}_{\mathrm{dc}}\right)$ & $300[\mathrm{~V}]$ \\
\hline Load resistance $\left(\mathrm{R}_{\mathrm{s}}\right)$ & $5.5[\Omega]$ \\
\hline Load inductance $\left(\mathrm{L}_{\mathrm{s}}\right)$ & $41[\mathrm{mH}]$ \\
\hline Poles & 48 \\
\hline Shunt resistance $\left(\mathrm{R}_{\mathrm{shunt}}\right)$ & $40[\mathrm{~m} \Omega]$ \\
\hline Switching period $\left(\mathrm{T}_{\mathrm{sw}}\right)$ & $62.5[\mu \mathrm{s}]$ \\
\hline Minimum duration $\left(\mathrm{T}_{\min }\right)$ & $8[\mu \mathrm{s}]$ \\
\hline Operating frequency $(\mathrm{f})$ & $\sim 480[\mathrm{~Hz}]$ \\
\hline
\end{tabular}

immeasurable areas can be reduced. Equations (4) through (6) provide the boundary conditions. The resultant areas are demonstrated in sky-blue in Fig. 8. The immeasurable areas are decreased by half when compared to those of the SVPWM in Fig. 6(b).

$$
\begin{aligned}
& T_{b}{ }^{\prime}=T_{1}+2 T_{0}<T_{\min } \\
& 2 T_{0}+T_{1}+T_{2}=\frac{T_{s w}}{2}
\end{aligned}
$$

The result of equating (4) and (5), is as follows. :

$$
T_{2}>\frac{T_{s w}}{2}-T_{\min }
$$

Incidentally, the influences of the immeasurable areas may not appear depending on the system specifications. The boundary magnitudes for the proper operation of the TSSI, are 


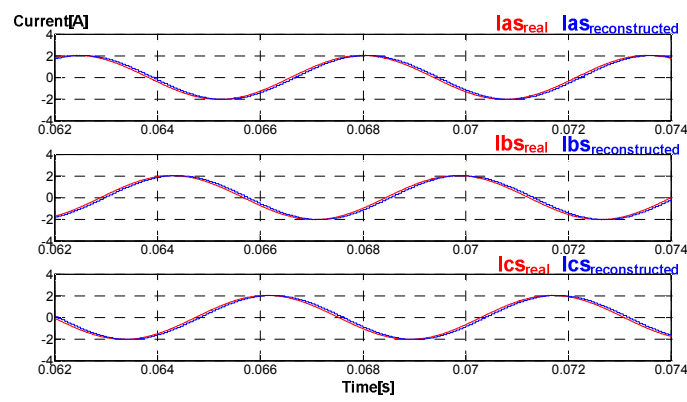

(a)

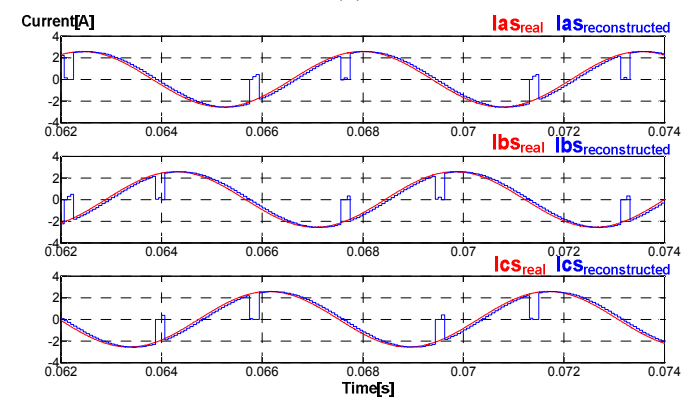

(b)

Fig. 11. Current reconstruction for SVPWM with different voltage reference magnitudes of (a) $r=95[\mathrm{~V}]$ and (b) $r=120[\mathrm{~V}]$.

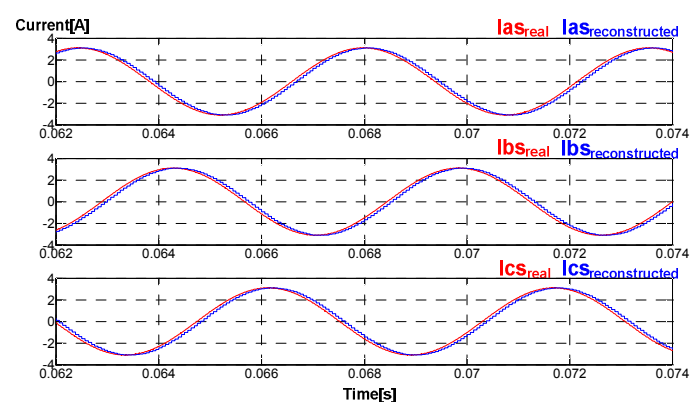

(a)

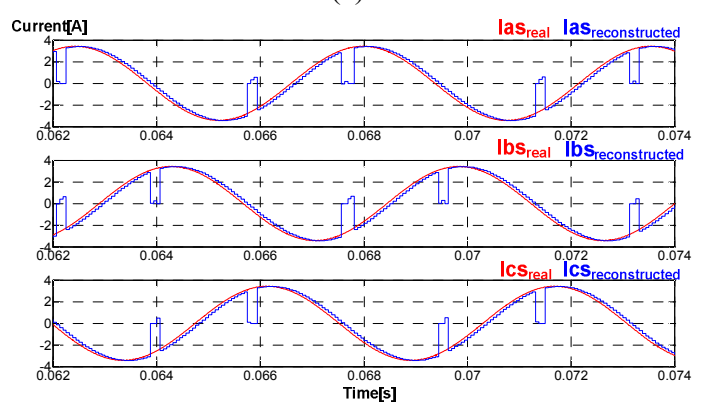

(b)

Fig. 12. Current reconstruction for DPWM with different voltage reference magnitudes of (a) $r=145[\mathrm{~V}]$ and (b) $r=160[\mathrm{~V}]$.

shown in Fig. 9, according to the PWM methods. If it is assumed that the inverter operates only in a linear region, then the maximum magnitude of the voltage reference is less than $\mathrm{V}_{\mathrm{dc}} / \sqrt{3}$. Hence when the boundary magnitudes are larger than $\mathrm{V}_{\mathrm{dc}} / \sqrt{3}$, the phase currents can be reconstructed for all operating conditions and there is no need to compensate for the distortions of the reconstructed phase

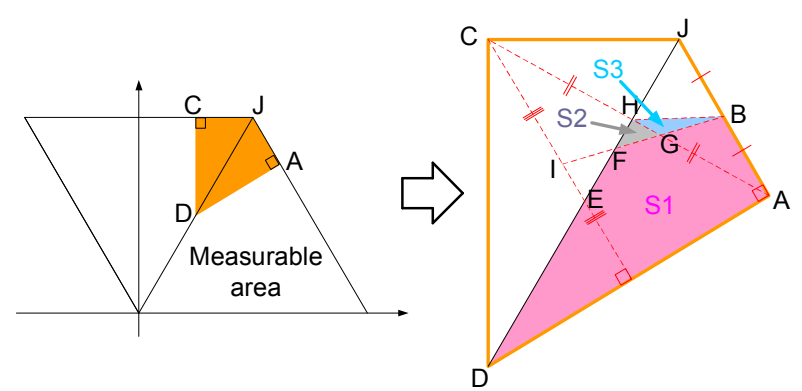

Fig. 13. Immeasurable area division for SVPWM.

currents.

\section{B. Identification of the Boundary Areas}

To verify the boundary derivation of the TSSI, simulations were conducted with the system specifications (for a washing machine application) shown in Table II. Theoretically, the maximum magnitudes of the voltage references with SVPWM and DPWM for accurate phase current reconstruction were determined to be 97.6 [V] and 148.8 [V], respectively, as shown in Fig. 10. The performances of the phase current reconstruction for each of the PWM methods are presented in Fig. 11 and Fig. 12.

For SVPWM, while there should be no error in the reconstructed phase currents when the magnitude of the voltage reference is less than 97.6 [V], the reconstructed phase currents are assumed to be different from the actual phase currents when the magnitude of the voltage reference exceeds 97.6 [V]. To confirm this failure of the reconstruction performance, a comparatively high voltage of 120 [V] is applied. The reconstructed currents of the two phases show zero clamping phenomena, as shown in Fig. 11(b). This is the result when current sampling is conducted after the lower switch in the corresponding phase is turned off. If the resonance effect is included in the simulation, more realistic waveforms can be obtained. This is demonstrated in the experimental results.

\section{EXPANSION OF THE MEASURABLE AREAS}

The immeasurable areas derived previously can be reduced by voltage injection and compensation. To minimize the ripple currents, the minimum voltage is injected and compensated. Basically, when the voltage reference is in an immeasurable area, it is relocated to a measurable area by means of a voltage injection. To synthesize the original voltage in an average sense, a reverse voltage is also injected as a compensating method. Injection and compensation are conducted for every other half switching period. Specific methods are described below for SVPWM and DPWM.

\section{A. Voltage Injection for SVPWM}

To describe the voltage injection process, it is assumed, for example, that the reference voltage is in sector 1 . However, for other sectors, the same approach can be applied. As shown in Fig. 13, the immeasurable area can be divided into three 


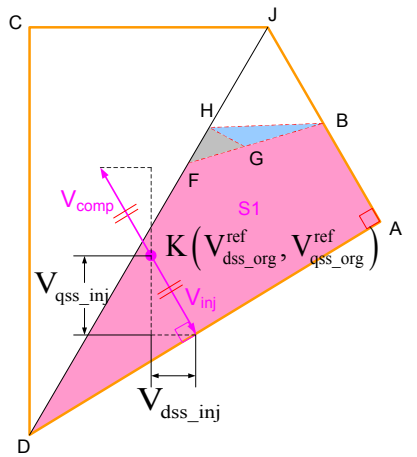

(a)

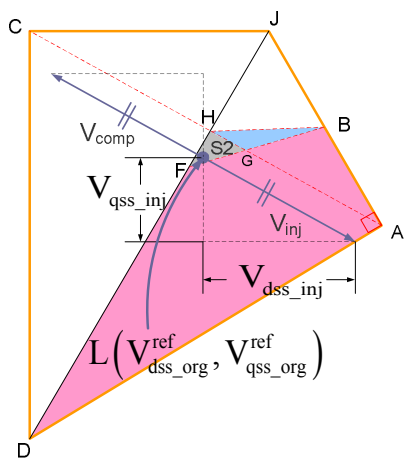

(b)

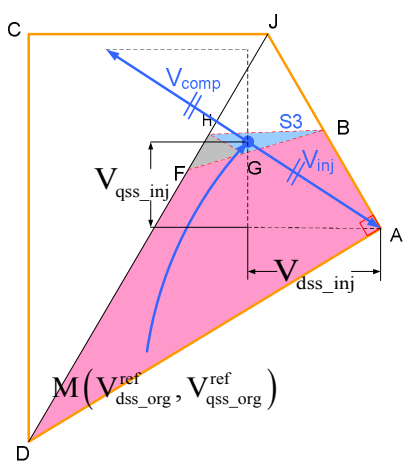

(c)

Fig. 14. Proposed voltage injection/compensation method for SVPWM when the original voltage reference is in (a) S1, (b) S2, and (c) S3.

sub-areas according to the different voltage injection modes. First, when the voltage vector lies in area S1, which is surrounded by $\square$ ABFD, the voltage is injected as shown in Fig. 14(a), where the line connecting the original point and the injected point is perpendicular to the measurable boundary line $\overline{\mathrm{AD}}$. In this way, the magnitude of the injected voltage is minimized and, consequently, the current ripples resulting from the injection can be minimized.

If the same injection and compensation approach is applied when the voltage reference is in $\mathrm{S} 2(\triangle \mathrm{FGH})$ or $\mathrm{S} 3(\triangle \mathrm{BGH})$, the compensated voltage vector would be out of the hexagon. Therefore, it cannot be synthesized by PWM. This leads to an imbalance between the injection and the compensation. As a
TABLE III

INJECTED VOLTAGES IN D-Q STATIONARY REFERENCE FRAME FOR SECTOR 1 FOR SVPWM

(VDSS INJ/VQSS INJ : INJECTION VOLTAGES IN D-Q AXIS STATIONARY REFERENCE FRAME,

VREFDSS ORG/VREFQSS ORG : ORIGINAL VOLTAGE REFERENCE IN D-Q AXIS STATIONARY REFERENCE FRAME)

\begin{tabular}{|c|c|}
\hline Sub-area & Injected voltages \\
\hline S1 & 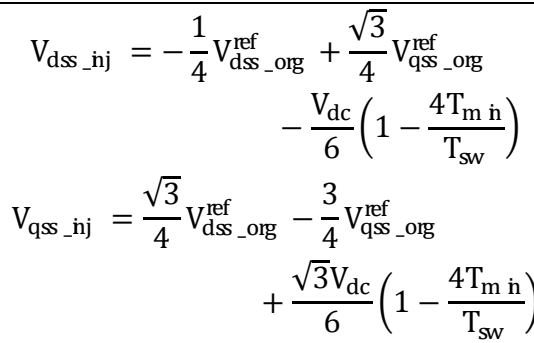 \\
\hline $\mathrm{S} 2$ & 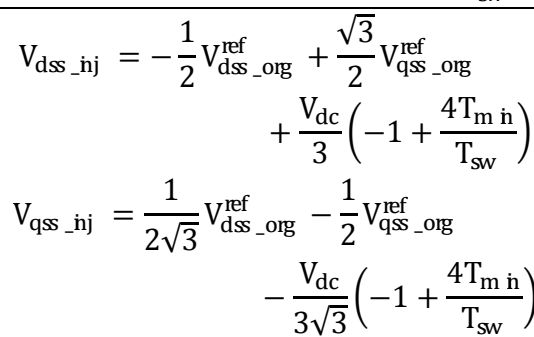 \\
\hline $\mathrm{S} 3$ & 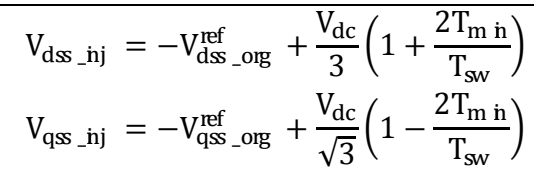 \\
\hline
\end{tabular}

result, when the voltage vector lies in S2 or S3, another approach should be implemented.

When the reference exists in S2, the voltage can be injected parallel to line $\overline{\mathrm{AC}}$, as shown in Fig. 14(b). This is the minimum magnitude for perfect compensation. Similarly, when the reference is placed in S3, the nearest point for injection becomes point A, as shown in Fig. 14(c). Finally, the immeasurable area is reduced to $\triangle \mathrm{BHJ}$, which is $1 / 8$ the original size of the immeasurable area.

The injection voltages for sector 1 in the d-q stationary reference frame are summarized in Table III. For sector 2, similar considerations can be taken into account, showing that it is reasonable to inject voltages symmetrically to line $\overline{\mathrm{JD}}$ for each sub-area. For the other sectors in pairs (sector 3 and sector $4 \&$ sector 5 and sector 6), angle rotation can be used with the calculated injection voltages for sector 1 and sector 2 due to their geometric identities. This is beneficial for decreasing the calculation time and for reducing the complexity of the implementation.

\section{B. Voltage Injection for DPWM}

Similar approaches can be adopted to expand the measurable areas for DPWM. The original immeasurable area 


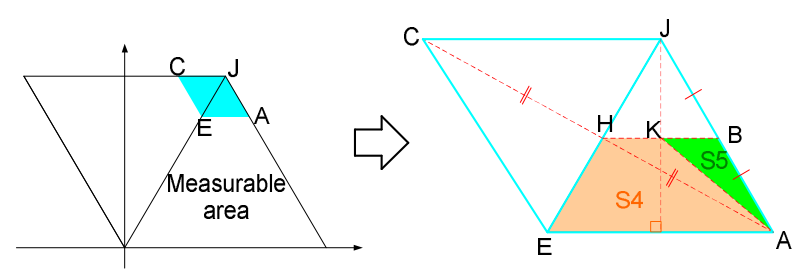

Fig. 15. Immeasurable area division for DPWM.

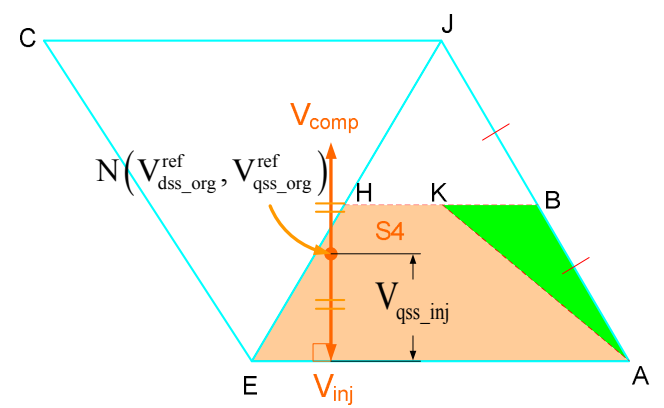

(a)

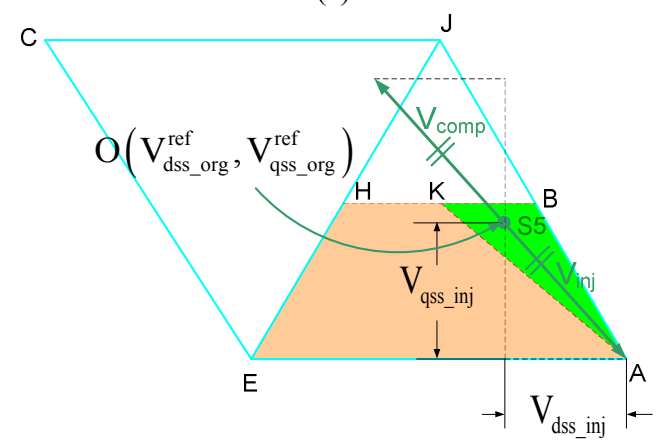

(b)

Fig. 16. Proposed voltage injection/compensation method for DPWM when the original voltage reference is in (a) S4 and (b) S5.

is divided into two sub-areas, as shown in Fig. 15, depending on the voltage injection mode. When the original reference voltage vector is placed in S4(口AEHK), the orthogonal point to line $\overline{\mathrm{AE}}$ from the original reference point is optimal in terms of the minimum magnitude of the injection voltage. Therefore, when the original reference voltage vector is in sector 1 , there is no injection voltage in the d-axis and only the q-axis injection voltage exists, as shown in Fig. 16(a). In the case of S5, point A is chosen for the injection to keep the compensated point within the voltage hexagon. This process is depicted in Fig. 16(b). Consequently, the final immeasurable area is identical to that of SVPWM, $\triangle \mathrm{BHJ}$, which is $1 / 4$ the original immeasurable area.

The injection voltages for sector 1 in the d-q stationary reference frame are summarized in Table IV. As in SVPWM, for sector 2 the symmetric voltages to line $\overline{\mathrm{JE}}$ can be injected for each sub-area. The same angle rotation used for SVPWM can also be applied for other sectors. As can be expected from the boundary figure, less voltage is injected in DPWM than in SVPWM owing to the smaller immeasurable area. This reduces the current ripples caused by the injection.

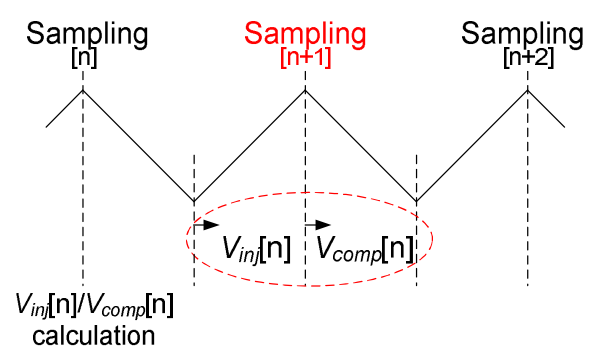

(a)

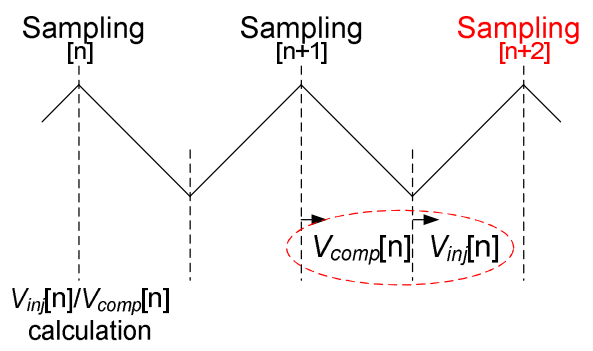

(b)

Fig. 17. Injection timing of two different sampling basis implementations. : (a) Injection first case and (b) compensation first case.

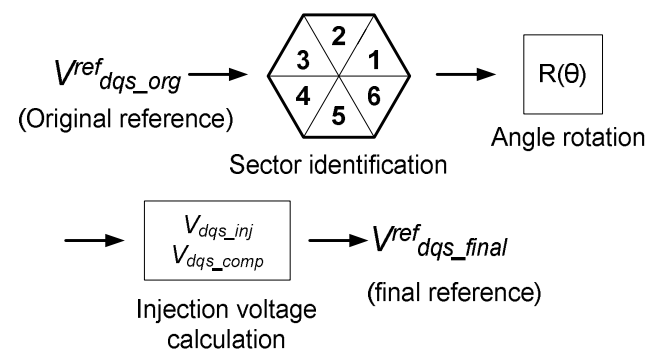

Fig. 18. Realization of the proposed method.

\section{Implementation of the Proposed Method}

Fig. 17 shows two different feasible implementations of the proposed method in terms of the sampling basis. The only difference between them is the time at which the voltage injection is realized. If the injection comes before the compensation, as shown in Fig. 17(a), the sampling delay is $\mathrm{T}_{\mathrm{sw}}$ and the sampled current is not the average value due to the injected voltage. On the other hand, if the injection follows the compensation, as shown in Fig. 17(b), the sampling delay is $2 \mathrm{~T}_{\mathrm{sw}}$ but the sampled current is the average value. The difference between the two implementations becomes more significant at a lower switching frequency and with a larger ' $\mathrm{T}_{\text {min }}$ '. In the system considered in this study, given that the switching frequency is sufficiently high and because ' $T_{\min }$ ' is assumed to be reasonably short, there is no conspicuous difference. Thus the method in Fig. 17(b) is used as the implementation method for the proposed injection and compensation scheme. In addition, the compensation is conducted within one sampling period, and the voltage injection has an insignificant effect on the current control performance as long as the ratio of the switching frequency to the fundamental operating frequency is sufficiently large.

Fig. 18 depicts the overall procedure for the proposed 


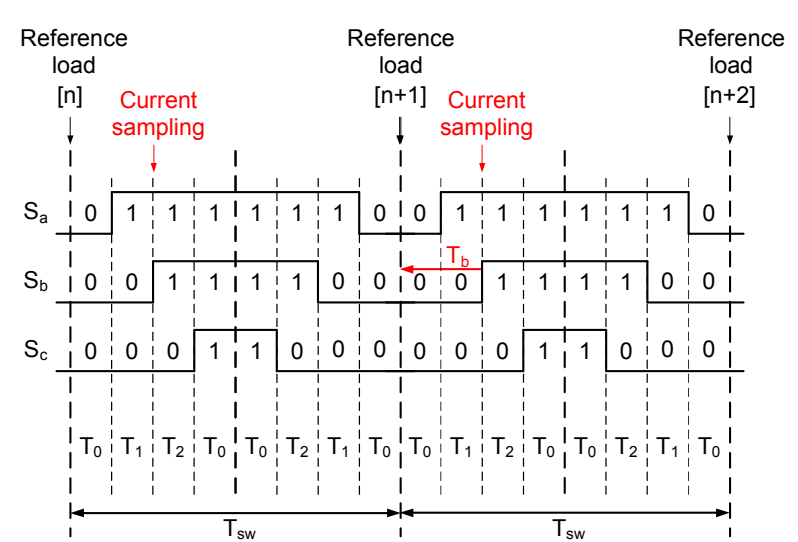

Fig. 19. Time shifting for the measurement in sector 1 with SVPWM.

\section{TABLE IV}

InJeCted Voltages in D-Q STATIONARY REFERENCE Frame FOR SECTOR 1 FOR DPWM

\begin{tabular}{|c|c|}
\hline Sub-area & Injected voltages \\
\hline $\mathrm{S} 4$ & $\mathrm{~V}_{\mathrm{dss} \_\mathrm{nj}}=0$ \\
\hline $\mathrm{S} 5$ & $\mathrm{~V}_{\mathrm{qss} \_\mathrm{nj}}=-\mathrm{V}_{\mathrm{qss} \_ \text {org }}^{\mathrm{ref}}+\frac{\mathrm{V}_{\mathrm{dc}}}{\sqrt{3}}\left(1-\frac{2 \mathrm{~T}_{\mathrm{m} \text { i }}}{\mathrm{T}_{\mathrm{sw}}}\right)$ \\
\hline $\mathrm{V}_{\mathrm{dss} \_\mathrm{nj}}=-\mathrm{V}_{\mathrm{dss} \_ \text {org }}^{\mathrm{ref}}+\frac{\mathrm{V}_{\mathrm{dc}}}{3}\left(1+\frac{2 \mathrm{~T}_{\mathrm{m} \mathrm{n}}}{\mathrm{T}_{\mathrm{sw}}}\right)$ \\
$\mathrm{V}_{\mathrm{qss} \_\mathrm{nj}}=-\mathrm{V}_{\mathrm{q} \mathrm{rs} \_ \text {org }}^{\mathrm{ref}}+\frac{\mathrm{V}_{\mathrm{dc}}}{\sqrt{3}}\left(1-\frac{2 \mathrm{~T}_{\mathrm{m} \mathrm{n}}}{\mathrm{T}_{\mathrm{sw}}}\right)$ \\
\hline
\end{tabular}

method, including the angle rotation process. Fundamentally, the injection and compensation voltages are computed only for sectors 1 and 2 . These voltages are then shifted $2 \pi / 3$ clockwise for sectors 5 and 6 . For sectors 3 and 4 , a $2 \pi / 3$ counter clockwise angle shift is enacted.

\section{Measurement by the Instant Shifting Method}

By shifting the sampling point of the shunt currents, the immeasurable areas can be reduced further. If the current is sampled as in Fig. 19 for SVPWM, in contrast to that shown in Fig. 4(b), $\mathrm{T}_{\mathrm{b}}$ needs to be longer than $0.5 \mathrm{~T}_{\min }$ under the assumption that the switching states of switches between two consecutive switching periods change only by a negligible amount. This condition arises because $0.5 \mathrm{~T}_{\min }$ is secured during the previous switching period. Therefore, $0.5 \mathrm{~T}_{\min }$ is sufficient for the next switching period to reconstruct the phase currents precisely. The sampling period still remains constant, and there is no digital delay to be added in comparison with the non-shifting case. One disadvantage is that the sampled current is not the average value within the switching period in this method.

The mathematical expressions of equations (1) - (3) are modified to (7) - (9), and the final immeasurable areas then become half of the areas in Fig. 6.

$$
T_{b}=T_{0}+T_{1}<0.5 T_{\min }
$$

$$
2 T_{0}+T_{1}+T_{2}=\frac{T_{s w}}{2}
$$

The result of equating (7) and (8), is as follows. :

$$
T_{2}>T_{1}+\frac{T_{s w}}{2}-T_{\min }
$$

Similarly, the same idea can be applied to the case of DPWM. The immeasurable areas can be easily derived by substituting $0.5 \mathrm{~T}_{\min }$ for $\mathrm{T}_{\min }$ in (4).

In addition to the above sampling point shifting process for shunt measurement, the proposed voltage injection method can still be applied. The reduced immeasurable areas are defined by revised boundary equations and the injection voltages are derived based on the boundary conditions. In conclusion, the final immeasurable areas are reduced by half of $\triangle \mathrm{BHJ}$ in Fig. 13.

The sampling point shifting of the shunt currents guarantees theoretically the smallest immeasurable areas without a voltage injection. Thus TSSI is feasible in most operating ranges.

\section{SIMULATION AND EXPERIMENTAL RESUlTS}

The effectiveness of the proposed voltage injection method is verified by simulations and experiments. For the simulations and experiments, the fundamental voltage references were determined in the open loop control system and the calculated injection/compensation voltages were added to the original voltage references. To evaluate the proposed method, the reconstructed phase current waveforms are compared to the actual phase currents. Fig. 20 shows the SVPWM simulation results, where the magnitude of the voltage reference vector is 120 [V]. As shown in Fig. 20(a), the phase currents are accurately reconstructed when compared to Fig. 11. The injected voltages in the stationary $\mathrm{d}-\mathrm{q}$ reference frames are displayed in Fig. 20(b). In addition, the locus of the revised reference voltage vector is presented in Fig. 20(c) to note the injection/compensation effect.

The experimental results in Fig. 21 support the validity of the proposed method for SVPWM. When a voltage reference with a magnitude of 140 [V] is applied without a voltage injection, the current of phase ' $a$ ' is erroneously reconstructed, as shown in Fig. 21(a). However, the reconstruction performance greatly improves, as shown in Fig. 21(b), with the injected voltages shown in Fig. 21(c).

For DPWM, the proposed method was also confirmed, as shown in Fig. 22 and Fig. 23. Because the shapes of the immeasurable areas differ from those of SVPWM, the voltage reference locus is also different. The distortion in the reconstructed current in the experiment is less significant, as the immeasurable areas are relatively small. Therefore, smaller voltages are injected. The phase current reconstruction performance is satisfactory in both the simulation and the experimental results. 


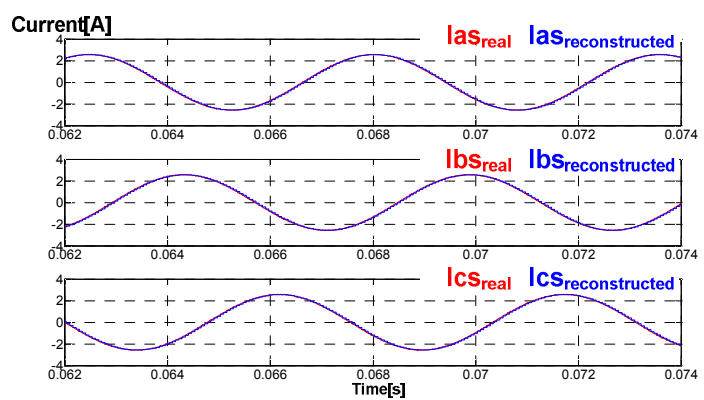

(a)

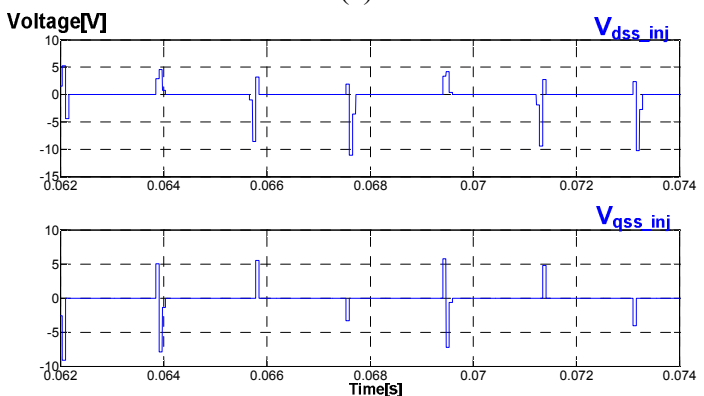

(b)

Fig. 20. Simulation results for the proposed method in SVPWM, where $\mathrm{r}=120[\mathrm{~V}]$ and $\mathrm{f}=180[\mathrm{~Hz}]$. : (a) Current waveforms reconstructed by the proposed method and (b) the injected voltages.

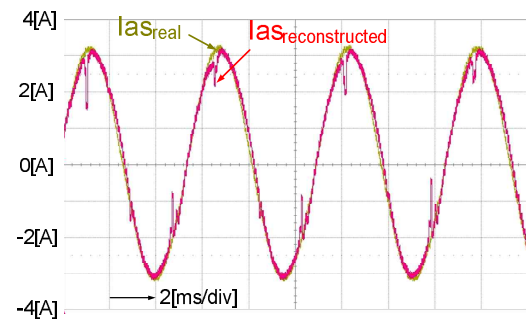

(a)

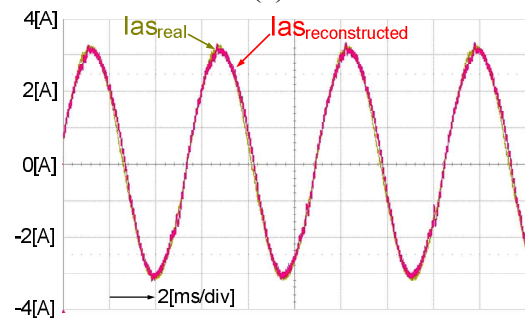

(b)

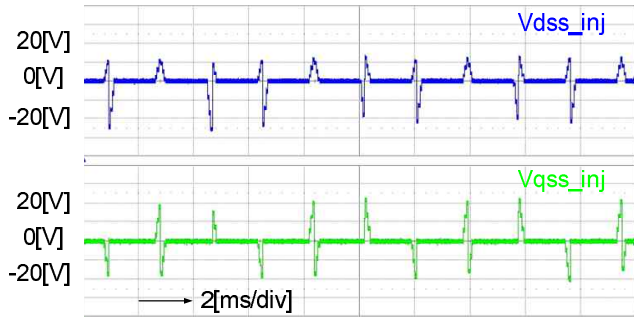

(c)

Fig. 21. Experimental results for the proposed method in SVPWM, where $\mathrm{r}=140[\mathrm{~V}]$ and $\mathrm{f}=180[\mathrm{~Hz}]$. : (a) Current waveforms reconstructed without a voltage injection, (b) with the voltage injection, and (c) the injected voltages.

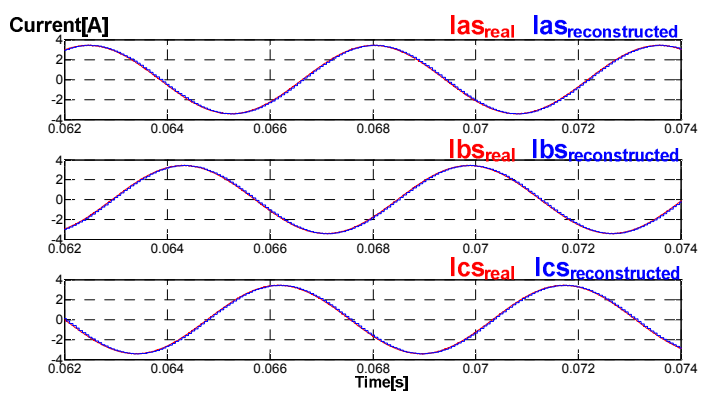

(a)

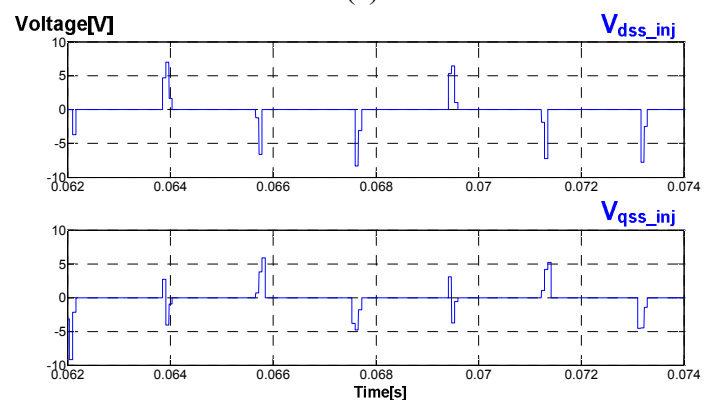

(b)

Fig. 22. Simulation results for the proposed method in DPWM, where $\mathrm{r}=160[\mathrm{~V}]$ and $\mathrm{f}=180[\mathrm{~Hz}] .:$ (a) Current waveforms reconstructed by the proposed method and (b) the injected voltages.

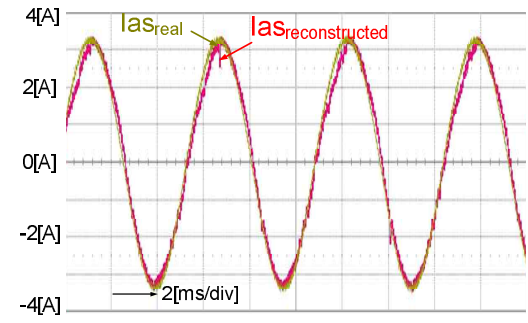

(a)

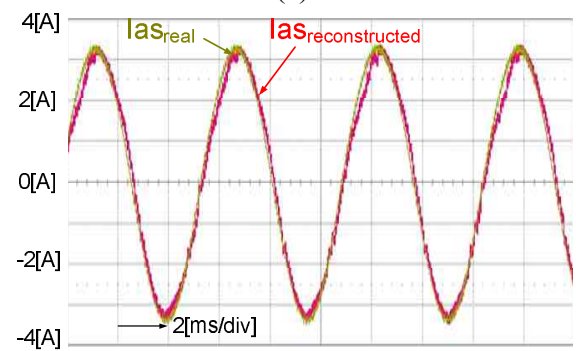

(b)

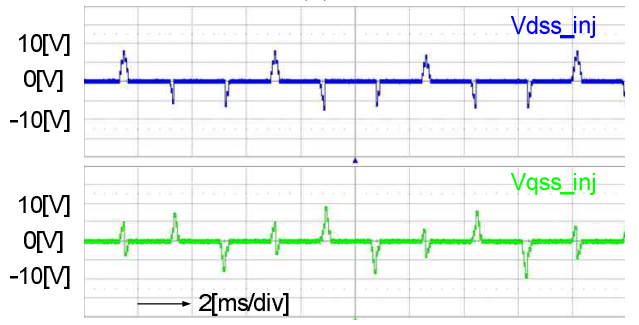

(c)

Fig. 23. Experimental results for the proposed method in DPWM, where $\mathrm{r}=155[\mathrm{~V}]$ and $\mathrm{f}=180[\mathrm{~Hz}]$. : (a) Current waveforms reconstructed without a voltage injection, (b) with the voltage injection, and (c) the injected voltages. 


\section{CONCLUSIONS}

In this paper, the boundary conditions for the phase current reconstruction of a three-shunt sensing inverter (TSSI) were analytically derived. For given system specifications, the immeasurable areas can be defined according to the PWM method and phase current reconstruction is impossible in those areas. This paper proposes a voltage injection method for the enhancement of the phase current reconstruction in the immeasurable areas for SVPWM and DPWM. To minimize the side effects of the voltage injection, the minimum magnitude voltage is selected. The effectiveness of the proposed method is verified by simulations and experimental results. By shifting the sampling point of the shunt currents, the immeasurable areas are halved.

\section{REFERENCES}

[1] C. Xiao, L. Zhao, T. Asada, W.G. Odendaal, and J. D. Van Wyk, "An overview of integratable current sensor technologies," Industry Applications Conference, 2003. 38th IAS Annual Meeting, Vol. 2, pp. 1251-1258, Oct. 2003.

[2] S. Chakrabarti, T.M. Jahns, and R. D. Lorenz, “A current reconstruction algorithm for three-phase inverters using integrated current sensors in the low-side switches," Industry Applications Conference, 2003. 38th IAS Annual Meeting, pp. 925- 932 Vol. 2, Oct. 2003.

[3] S. Chakrabarti, T. M. Jahns, and R. D. Lorenz, "Reduction of parameter sensitivity in an induction motor current regulator using integrated pilot sensors in the low-side switches," IEEE Trans. Ind. Appl., Vol. 41, No. 6, pp. 1656- 1666, Nov./Dec. 2005.

[4] S. Chakrabarti, T. M. Jahns, and R. D. Lorenz, "A current control technique for induction machine drives using integrated pilot current sensors in the low-side switches," IEEE Trans. Power Electron., Vol. 22, No. 1, pp.272-281, Jan. 2007.

[5] T. C. Green and B. W. Williams, "Derivation of motor line-current waveforms from the DC-link current of an inverter," Electric Power Applications, IEE Proceedings B, Vol. 136, No. 4, pp. 196-204, Jul. 1989.

[6] Y. Xue, X. Xu, T.G. Habetler. and D.M. Divan, "A low cost stator flux oriented voltage source variable speed drive," Industry Applications Society Annual Meeting, 1990., Conference Record of the 1990 IEEE, pp. 410-415 Vol. 1, Oct. 1990.

[7] T. G. Habetler and D. M. Divan, "Control strategies for direct torque control using discrete pulse modulation," IEEE Trans. Ind. Appl., Vol. 27, No. 5, pp. 893-901, Sep./Oct. 1991.

[8] F. Blaabjerg and J.K. Pedersen, "An ideal PWM-VSI inverter using only one current sensor in the DC-link," Power Electronics and Variable-Speed Drives, 1994. Fifth International Conference on, pp.458-464, Oct. 1994.

[9] H.-G. Joo, C.-G. Kim, H.-B. Shin, and M.-J. Youn, "Detection of three-phase currents in space-vector PWM inverters with only one DC link current sensor," Industrial Electronics, Control, and Instrumentation, 1996., Proceedings of the 1996 IEEE IECON 22nd International Conference on, pp.127-132, Vol. 1, Aug. 1996.

[10] F. Blaabjerg, J. K. Pedersen, U. Jaeger, and P.
Thoegersen, "Single current sensor technique in the DC-link of three-phase PWM-VS inverters. A review and the ultimate solution," Industry Applications Conference, 1996. Thirty-First IAS Annual Meeting, IAS '96., Conference Record of the 1996 IEEE, pp.1192-1202, Vol. 2, Oct. 1996.

[11] F. Blaabjerg and J. K. Pedersen, "A new low-cost, fully fault-protected PWM-VSI inverter with true phase-current information," IEEE Trans. Power Electron., Vol. 12, No. 1, pp. 187-197, Jan. 1997.

[12] B. Andersen, T. Holmgaard, J. G. Nielsen, and F. Blaabjerg, "Active three-phase rectifier with only one current sensor in the DC-link," Power Electronics and Drive Systems, PEDS '99, Proceedings of the IEEE 1999 International Conference, pp.69-74, Vol. 1, 1999.

[13] W.-C. Lee, D.-S. Hyun, and T.-K. Lee, "Single sensor current control of a three-phase voltage-source PWM converter using predictive state observer," Industrial Electronics Society, 1999. IECON '99 Proceedings. The 25th Annual Conference of the IEEE, pp.791-796, Vol. 2, 1999.

[14] W.-C. Lee, T.-J. Kweon, D.-S. Hyun, and T.-K. Lee, “A novel control of three-phase PWM rectifier using single current sensor," Power Electronics Specialists Conference, 1999. PESC 99. 30th Annual IEEE, pp.515-520 Vol. 1, Aug. 1999.

[15] W.-C. Lee, D.-S. Hyun, and T.-K. Lee, "A novel control method for three-phase PWM rectifiers using a single current sensor," IEEE Trans. Power Electron., Vol. 15, No. 5, pp.861-870, Sep. 2000.

[16] W.-C. Lee, T.-K. Lee, and D.-S. Hyun, "Comparison of single-sensor current control in the DC link for three-phase voltage-source PWM converters," IEEE Trans. Ind. Electron., Vol. 48, No. 3, pp. 491-505, Jun. 2001.

[17] T. M. Wolbank and P. E. Macheiner, "Current-controller with single DC link current measurement for inverter-fed AC machines based on an improved observer-structure," IEEE Trans. Power Electron., Vol. 19, No. 6, pp. 15621567, Nov. 2004.

[18] H.-S. Ryu, H.-S. Yoo, and J.-I. Ha, "Carrier-based signal injection method for harmonic suppression in PWM inverter using single dc-link current sensor," IEEE Industrial Electronics, IECON 2006 - 32nd Annual Conference on, pp.2700-2705, Nov. 2006.

[19] H. Kim and T. M. Jahns, "Phase current reconstruction for ac motor drives using a dc link single current sensor and measurement voltage vectors," IEEE Trans. Power Electron., Vol. 21, No. 5, pp.1413-1419, Sep. 2006.

[20] B. Saritha and P. A. Janakiraman, "Sinusoidal three-phase current reconstruction and control using a dc-link current sensor and a curve-fitting observer," IEEE Trans. Ind. Electron., Vol. 54, No. 5, pp.2657-2664, Oct. 2007.

[21] J.-I. Ha, "Voltage injection method for three-phase current reconstruction in pwm inverters using a single sensor," IEEE Trans. Power Electron., Vol. 24, No. 3, pp.767-775, Mar. 2009.

[22] F. Parasiliti, R. Petrella, and M. Tursini, "Low cost phase current sensing in DSP based AC drives," Industrial Electronics, 1999. ISIE '99. Proceedings of the IEEE International Symposium on, pp.1284-1289, Vol. 3, 1999.

[23] H. Kim, S. Yi, N. Kim, and R. D. Lorenz, "Using low resolution position sensors in bumpless position/speed estimation methods for low cost PMSM drives," Industry Applications Conference, 2005. Fourtieth IAS Annual Meeting. Conference Record of the 2005, Vol. 4, pp. 2518- 
2525, Oct. 2005.

[24] S. Chi, X. Wang, Y. Yuan, Z. Zhang, and L. Xu, "A current reconstruction scheme for low-cost PMSM drives using shunt resistors," Applied Power Electronics Conference, APEC 2007 - Twenty Second Annual IEEE, pp.1701-1706, Mar. 2007.

[25] B.-G. Cho, J.-I. Ha, and S.-K. Sul, "Voltage injection method for boundary expansion of output voltages in three shunt sensing PWM inverters," Power Electronics and ECCE Asia (ICPE \& ECCE), 2011 IEEE 8th International Conference on, pp.411-415, May/Jun. 2011.

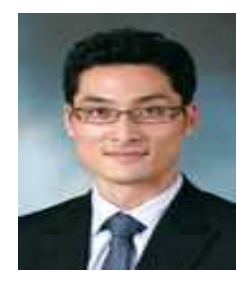

Byung-Geuk Cho was born in Busan, Korea, in 1980. He received his B.S. and M.S. in Electrical Engineering from Seoul National University, Seoul, Korea, in 2007 and 2009, respectively. He is currently working towards his Ph.D. at Seoul National University. His current research interests include high-power converter control and AC drive systems.

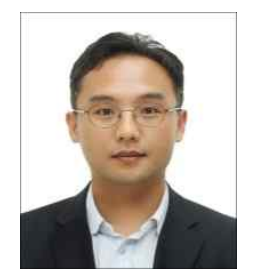

Jung-Ik Ha was born in Korea in 1971. He received his B.S., M.S., and Ph.D. in Electrical Engineering from Seoul National University, Seoul, Korea, in 1995, 1997, and 2001, respectively. From 2001 to 2002, he was a Researcher for Yaskawa Electric Co., Japan. From 2003 to 2008, he worked as a Senior and Principal Engineer for Samsung Electronics Co., Korea. From 2009 to 2010, he was a Chief Technology Officer for LS Mechapion Co., Korea. Since 2010, he has been an Assistant Professor in the School of Electrical Engineering, Seoul National University. His current research interests include circuits and control in high efficiency and integrated electric energy conversions for various industrial fields.

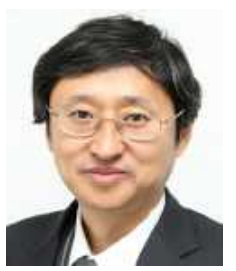

Seung-Ki Sul was born in Korea in 1958. He received his B.S., M.S., and Ph.D. in Electrical Engineering from Seoul National University, Seoul, Korea, in 1980, 1983, and 1986, respectively. From 1986 to 1988, he was an Associate Researcher in the Department of Electrical and Computer Engineering, University of Wisconsin, Madison, U.S.A. From 1988 to 1990, he was a Principal Research Engineer with Gold-Star Industrial Systems Co., Korea. Since 1991, he has been a member of the faculty in the School of Electrical Engineering, Seoul National University, where he is currently a Full Professor. Since 2000, he has been an IEEE Fellow. From 2003 to 2004, he was a Research Director and an Acting Consultant for Yaskawa Electric Co., Japan. From 2005 to 2007, he was the Vice Dean of the Engineering College of Seoul National University. Also, from 2008 to 2011, he was the President of the Electrical Engineering Science Research Institute funded by the Korean Government. He has published over 120 reviewed journal papers, mainly IEEE transactions. He was Technical Chair of the IEEE PESC2006 conference and General Chair of the IEEE ECCE-Asia 2011. He holds 13 U.S. patents, 4 Japanese patents, and has granted 36 Ph.D.s to students under his supervision. He is currently Editor-in-Chief of the Journal of Power Electronics, which is a SCIE registered journal, published by the Korean Power Electronics Institute, Seoul, Korea. 